\title{
Evaluasi Jaringan Closed Circuit Television (CCTV) di Institut Teknologi Sepuluh Nopember (ITS)
}

\author{
Istas Pratomo $^{1 *}$, Sakinah ${ }^{1}$, dan Achmad Affandi ${ }^{1}$ \\ ${ }^{1}$ Program Studi Telekomunikasi Multimedia, Fakultas Teknologi Elektro, \\ Institut Teknologi Sepuluh Nopember (ITS) \\ J1. Arief Rahman Hakim, Surabaya 60111 \\ *E-mail: istaspra@ee.its.ac.id
}

\begin{abstract}
Abstrak
Keamanan merupakan hal yang sangat penting ketika seseorang sedang melakukan aktivitas di mana pun, seperti di kampus. Jaringan CCTV merupakan sistem pengawasan yang menggunakan kamera video digital untuk merekam dan mengirimkan sinyal video ke tempat tertentu dalam sebuah sistem pengawasan yang terbatas untuk meningkatkan keamanan di ITS. Berdasakan Pemetaan, terdapat 54 CCTV tersebar di ITS yang terhubung dalam jaringan Local Area Network (LAN) ITS. CCTV yang beroperasi sebanyak 28 buah, dengan throughput dikategorikan Sangat Bagus (diatas $1200 \mathrm{kBps}$ ) dan jitter dikategorikan Bagus (diantara 0-75 ms) menurut Telecommunications and Internet Protocol Harmonization Over Network (TIPHON). Berdasarkan hasil pemetaan dan pengukuran diketahui sistem monitoring CCTV di ITS tidak berjalan dengan baik. Maka dirancang Web Monitoring CCTV di ITS (WEMITS) yang menampilkan rekaman CCTV dan memonitoring kondisi ON/OFF CCTV secara otomatis. Pada page Map, terdapat peta sebaran CCTV dengan indikator titik hijau untuk CCTV beroperasi dan indikator titik merah untuk CCTV tidak beroperasi, yang ditampilkan secara otomatis dimana informasi (indikator, daftar identitas CCTV, Internet Protocol/IP, dan lokasi CCTV yang tidak beroperasi) diperbarui saat menu diklik atau di-refresh. Website ini memiliki throughput maksimal $20 \mathrm{Mbps}$ dan jitter $0.9 \mathrm{~ms}$.
\end{abstract}

Kata Kunci: CCTV, Pemetaan, Pengukuran, WEMITS

\section{PENDAhuluan}

Keamanan merupakan hal yang sangat penting ketika seseorang sedang melakukan aktivitas di mana pun, seperti di lingkungan kampus. Kampus merupakan tempat terbuka bagi masyarakat umum sehingga menimbulkan kesempatan bagi orang tertentu untuk melakukan tindak kejahatan. Seringkali terjadi pencurian di lingkungan ITS baik siang maupun malam hari, sehingga dibutuhkan sistem pengawasan yang dapat memantau lingkungan kampus sepanjang hari. Hal ini diwujudkan dengan memasang dan mengembangkan jaringan Closed Circuit Television (CCTV).

CCTV merupakan sistem pengawasan menggunakan video kamera untuk menampilkan dan merekam gambar pada waktu dan tempat dimana perangkat tersebut terpasang. CCTV menggunakan sinyal yang bersifat tertutup atau rahasia, tidak seperti televisi biasa pada umumnya yang merupakan broadcast signal(Atmoko, 2012).

Terdapat 54 CCTV di ITS yang terhubung dalam Local Area Network (LAN) ITS. CCTV ini merekam kejadian yang terjadi pada waktu sekarang atau real time dan menyimpannya ke recording server. Video tersebut dikelola Video Management System (VMS) NUUO SCBIP dan ditampilkan pada empat display TV LED 60 inch di posko Satuan Keamanan Kampus (SKK). Namun terdapat beberapa CCTV yang tidak dapat menampilkan rekaman video disebabkan mengalami gangguan, sehingga pemantauan keamanan di lingkungan di ITS tidak maksimal dan dapat menimbulkam potensi meningkatnya tindak pencurian di ITS. 
Pada paper ini difokuskan membahas evaluasi dengan pemetaan jaringan CCTV dan pengukuran kinerja jaringan meliputi throughput dan jitter untuk mengetahui masalah pada sistem pengawasan keamanan di ITS, serta rancangan sistem monitoring CCTV ITS untuk membantu petugas monitoring agar keamanan di lingkungan Institut Teknologi Sepuluh Nopember (ITS) lebih meningkat.

\section{METODOLOGI}

\section{A. Pemetaan}

Berdasarkan survei exsiting jaringan, akan didapatkan informasi mengenai lokasi, jenis, media transmisi dan kondisi ON/OFF CCTV.

Tabel 1. Pemetaan elemen jaringan CCTV ITS

\begin{tabular}{|c|c|c|c|c|}
\hline No & Identitas & $\begin{array}{c}\text { Jenis } \\
\text { CCTV }\end{array}$ & $\begin{array}{c}\text { Media } \\
\text { Transmisi } \\
\end{array}$ & Kondisi \\
\hline 1. & CCTV 1 & Outdoor & Fiber Optik & $\mathrm{ON}$ \\
\hline 2. & CCTV 2 & Outdoor & Fiber Optik & $\mathrm{ON}$ \\
\hline 3. & CCTV 3 & Outdoor & Fiber Optik & OFF \\
\hline 4. & CCTV 4 & Outdoor & Fiber Optik & OFF \\
\hline 5. & CCTV 9 & Outdoor & Fiber Optik & OFF \\
\hline 6. & CCTV 10 & Outdoor & Fiber Optik & OFF \\
\hline 7. & CCTV 12 & Outdoor & Fiber Optik & OFF \\
\hline 8. & CCTV 16 & Outdoor & Wireless & OFF \\
\hline 9. & CCTV 17 & Outdoor & Wireless & $\mathrm{ON}$ \\
\hline 10. & CCTV 18 & Outdoor & Wireless & OFF \\
\hline 11. & CCTV 19 & Outdoor & Wireless & OFF \\
\hline 12. & CCTV 20 & Outdoor & Wireless & OFF \\
\hline 13. & CCTV 21 & Outdoor & Wireless & OFF \\
\hline 14. & CCTV 22 & Outdoor & Wireless & $\mathrm{ON}$ \\
\hline 15. & CCTV 23 & Outdoor & Fiber Optik & OFF \\
\hline 16. & CCTV 24 & Outdoor & Fiber Optik & $\mathrm{ON}$ \\
\hline 17. & industri & Indoor & UTP & OFF \\
\hline 18. & industri2 & Indoor & UTP & OFF \\
\hline 19. & industri3 & Outdoor & Fiber Optik & OFF \\
\hline 20. & system_informasil & Indoor & UTP & $\mathrm{ON}$ \\
\hline 21. & system_informasi2 & Indoor & UTP & $\mathrm{ON}$ \\
\hline 22. & system_informasi3 & Outdoor & Fiber Optik & $\mathrm{ON}$ \\
\hline 23. & d3 fti_1 & Indoor & UTP & $\mathrm{ON}$ \\
\hline 24. & $\mathrm{~d} 3$ fti_2 & Indoor & UTP & $\mathrm{ON}$ \\
\hline 25. & $\mathrm{~d} 3 \mathrm{fti} 3$ & Outdoor & Fiber Optik & $\mathrm{ON}$ \\
\hline 26. & lingkungan1 & Indoor & UTP & OFF \\
\hline 27. & lingkungan2 & Indoor & UTP & OFF \\
\hline 28. & lingkungan3 & Outdoor & Fiber Optik & OFF \\
\hline 29. & rektorat1 & Indoor & UTP & $\mathrm{ON}$ \\
\hline 30. & rektorat2 & Indoor & UTP & $\mathrm{ON}$ \\
\hline 31. & rektorat3 & Outdoor & Fiber Optik & $\mathrm{ON}$ \\
\hline 32. & masjid1 & Indoor & UTP & $\mathrm{ON}$ \\
\hline 33. & masjid2 & Indoor & UTP & $\mathrm{ON}$ \\
\hline 34. & masjid3 & Outdoor & Fiber Optik & $\mathrm{ON}$ \\
\hline 35. & despro1 & Indoor & UTP & $\mathrm{ON}$ \\
\hline 36. & despro2 & Indoor & UTP & $\mathrm{ON}$ \\
\hline 37. & despro3 & Outdoor & Fiber Optik & $\mathrm{ON}$ \\
\hline 38. & perkapalan1 & Indoor & UTP & $\mathrm{ON}$ \\
\hline 39. & perkapalan2 & Indoor & UTP & OFF \\
\hline
\end{tabular}




\begin{tabular}{|l|l|l|c|c|}
\hline 40. & perkapalan3 & Outdoor & Fiber Optik & OFF \\
\hline 41. & kelautan1 & Indoor & UTP & ON \\
\hline 42. & kelautan2 & Indoor & UTP & ON \\
\hline 43. & kelautan3 & Outdoor & Fiber Optik & ON \\
\hline 44. & material1 & Indoor & UTP & OFF \\
\hline 45. & material2 & Indoor & UTP & OFF \\
\hline 46. & material3 & Outdoor & Fiber Optik & OFF \\
\hline 47. & Biologi1 & Indoor & UTP & ON \\
\hline 48. & Biologi2 & Indoor & UTP & ON \\
\hline 49. & Biologi3 & Outdoor & Fiber Optik & OFF \\
\hline 50. & Matematika1 & Indoor & UTP & OFF \\
\hline 51. & Matematika2 & Indoor & UTP & OFF \\
\hline 52. & Matematika3 & Outdoor & Fiber Optik & OFF \\
\hline 53. & Rektorat4 & Outdoor & Fiber Optik & ON \\
\hline 54. & arsitektek1 & Outdoor & Fiber Optik & ON \\
\hline
\end{tabular}

Dari tabel diatas dapat dilihat bahwa hampir setengah CCTV terpusat di ITS tidak beroperasi. CCTV yang beroperasi hanya $52 \%$ saja. Sementara itu CCTV yang tidak beroperasi diantaranya lima dari tujuh CCTV outdoor dengan medium wireless, 12 dari 23 CCTV outdoor dengan media transmisi fiber optic dan sembilan dari 24 CCTV dengan media transmisi kabel. Lalu, dari informSI lainnya yang didapat, dibuatlah topologi jaringan CCTV ITS untuk mengetahui struktur jaringan. Jika dilihat dari gambar, terlihat hirarki jaringan CCTV ITS terdiri atas tiga yaitu lapisan akses, lapisan distribusi dan lapiran inti. Pada lapisan akses, switch berhubungan langsung dengan end device yaitu IP based CCTV dan client. Setiap CCTV akan terhubung ke switch baik secara fisik (physical connect) maupun konfigurasi di perangkat switch (logical connect). Secara fisik, CCTV di setiap fakultas dihubungkan ke switch terdekat yaitu switch di fakultas tersebut menggunakan media transmisi. Sementara itu pada perangkat switch, IP CCTV dikonfigurasi agar berada dalam satu network dengan IP default gateway switch.

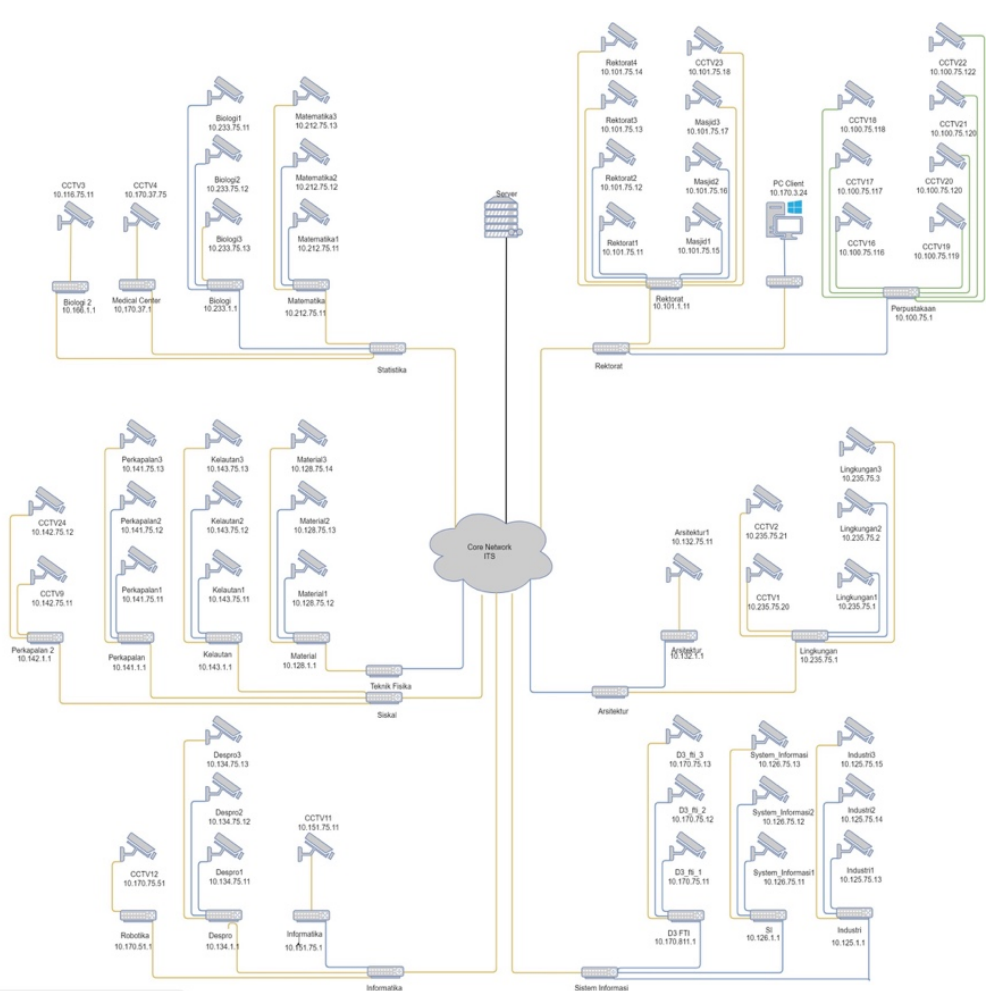

Gambar 1. Topologi Jaringan CCTV ITS 


\section{B. Pengukuran}

Pengukuran dilakukan di PC Client menggunakan software Wireshark terhadap setiap CCTV yang terhubung ke LAN ITS. Adapun parameter yang diukur adalah throughput, dan jitter. Berikut adalah diagram yang menunjukkan skenario pengukuran.

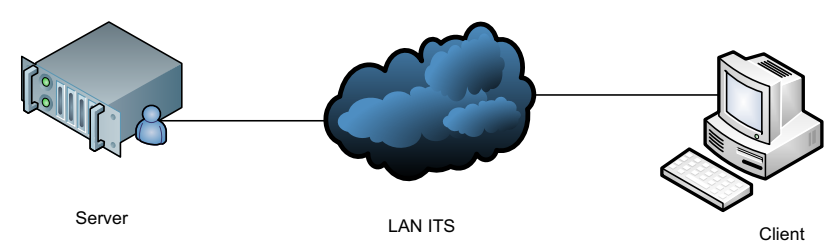

Gambar 2. Skenario Pengukuran Kinerja Jaringan

Langkah pengukuran adalah sebagai berikut. Masuk ke dalam aplikasi wireshark, lalu pilih interface yang akan digunakan, kemudian klik start. Setelah meng-capture lalu lintas data, perlu memfilter data yang akan dianalisis dengan mengisi kolom filter isi dengan tag di bawah ini.

tcp and ip.dst $==x x \cdot x x x \cdot x x \cdot x x$ and ip.src $==$

$x x . x x x . x x . x x x$

Setelah itu klik enter. Untuk mendapatkan nilai variabel yang dibutuhkan, buka toolbar wireshark klik tombol statistics lalu summary. Setelah mendapatkan data maka dihitung nilai throughput dan jitter sesuai dengan rumus.

\section{C.Perancangan Website}

Website yang diberi nama Web Monitoring CCTV ITS (WEMITS), dirancang memiliki lima page yaitu About, Home, Monitoring, Map dan Contact. Pengkodean atau coding dilakukan dengan bantuan software Macromedia Dreamweaver. Pengkodean website menggunakan bahasa pemrograman Hypertext Markup Language (HTML). Setiap dokumen HTML harus di awali dan di tutup dengan tag HTML seperti di bawah ini.

\section{$<$ html $></$ html $>$}

Bagian header dari dokumen HTML di apit oleh tag head di dalam bagian ini biasanya head dimuat tag tittle, tag meta dan Cascading Style Sheets (CSS) yang mengatur tampilan sebuah web menggunakan bahasa CSS.

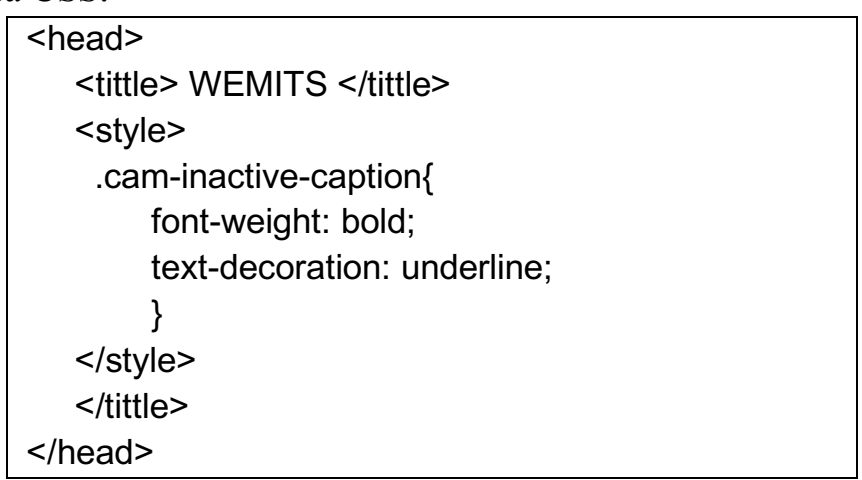


Bagian body di gunakan untuk menampilkan text, gambar, link, video, tabel, list, atau image link dan semua yang akan ditampilkan pada web page dengan tag terkait dan dapat mengembangkan dengan attribute dan value dari tag tersebut.

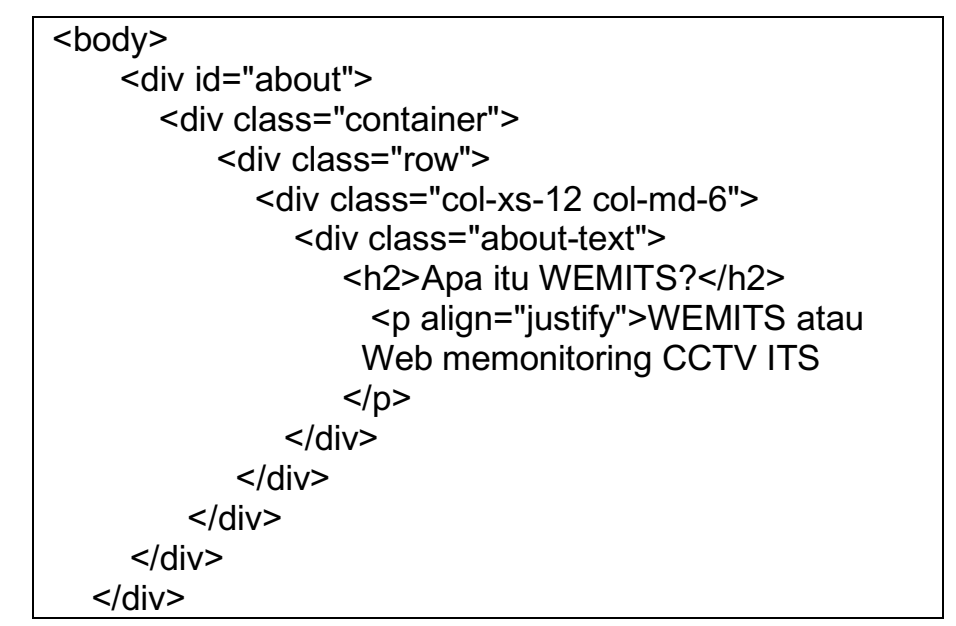

Sebelum menutup tag dengan $</ \mathrm{html}>$ biasanya ada tag script untuk memanggil java script atau script lain untuk membuat efek-efek interaktif tertentu baik di gambar maupun teks seperti tag dibawah ini.

<script type="text/javascript"src="js/bootstrap.js"></script>

\section{HASIL DAN PEMBAHASAN}

\section{A. Hasil dan Analisa Pengukuran}

Setelah melakukan perhitungan kinerja jaringan yang meliputi throughput dan jitter terhadap titik-titik CCTV yang masih aktif, maka dilakukan pengkategorian menurut standard TIPHON. Nilai throughput tertinggi berada pada titik CCTV2 (Gerbang Pos 1) yaitu $15080 \mathrm{Kbps}$ dan throughput terendah berada pada titik CCTV22 (BBPT) yaitu sebesar $1720 \mathrm{Kbps}$. Throughput tertinggi menggunakan media transmisi fiber optik sementara thoughput terendah menggunakan udara/wireless.

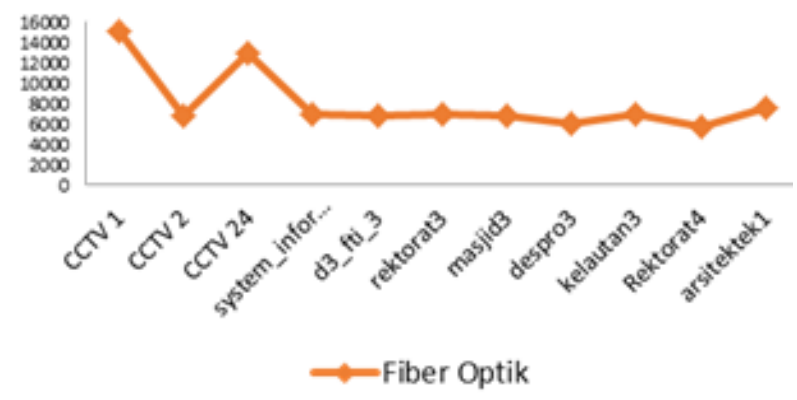

Gambar 3. Throughput CCTV medium Fiber Optik

Jika dilihat dari media transmisinya, fiber optik memiliki throughput berkisar 5700 - 15080 Kbps seperti terlihat pada Gambar 4.30. Nilai ini dapat dikategorikan Sangat Bagus menurut 
standard TIPHON. Sementara untuk media transmisi yang menggunakan kabel UTP, throughput berkisar antara 3330 - 7000 Kbps seperti dapat dilihat pada Gambar 4.31.

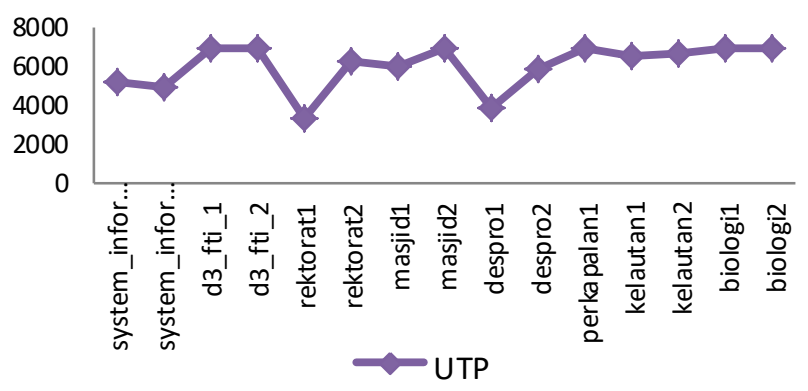

Gambar 4. Throughput CCTV medium kabel UTP

Untuk media transmisi wireless, throughput berkisar antara 1720 - $1820 \mathrm{Kbps}$ saja dimana nilai ini dapat dikategorikan Sangat Bagus. Nilai jitter paling rendah adalah $0.7 \mathrm{~ms}$ yaitu pada CCTV1 yang menggunakan media transmisi fiber optik. Nilai jitter paling besar adalah $6.5 \mathrm{~ms}$ yaitu pada CCTV22 yang menggunakan media transmisi wireless. Jika dilihat dari media transmisinya, fiber optik memiliki jitter berkisar antara $0.7-1.3 \mathrm{~ms}$ seperti yang terlihat pada Gambar 4.32 di bawah ini.

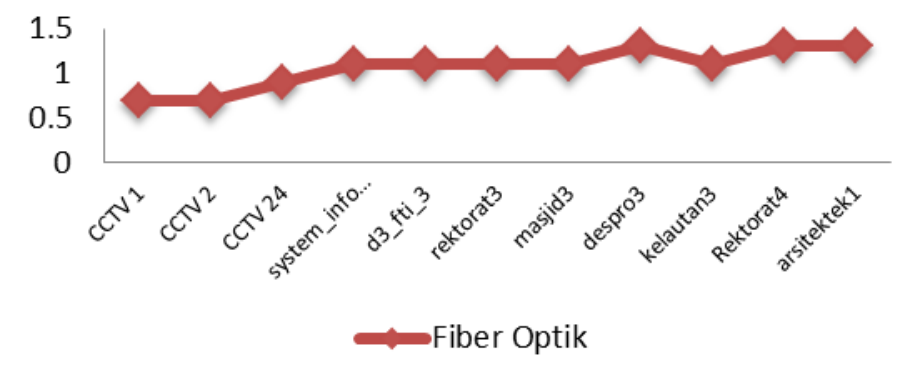

Gambar 5. Jitter CCTV dengan media transmisi fiber optik

Pada Gambar diatas, dapat dilihat bahwa jitter berkisar antara $1.1-2.5 \mathrm{~ms}$ lebih kecil jika dibandingkan dengan media transmisi wireless yang berkisar antara 6.3-6.5 ms. Namun nilai jitter pada ketiga media transmisi masih dikategorikan bagus menurut TIPHON.

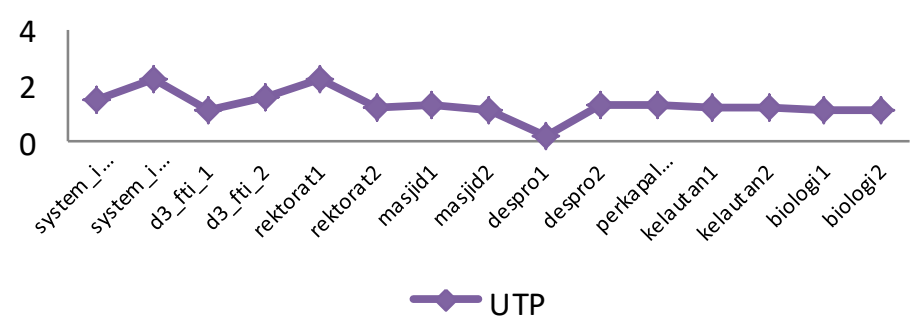

Gambar 6. Jitter CCTV dengan medium kabel UTP

\section{B. Pengujian dan Analisa Web}

Website yang dibuat diberi nama WEMITS yaitu singkatan dari Web Monitoring CCTV ITS dengan page Home seperti gambar di bawah. 


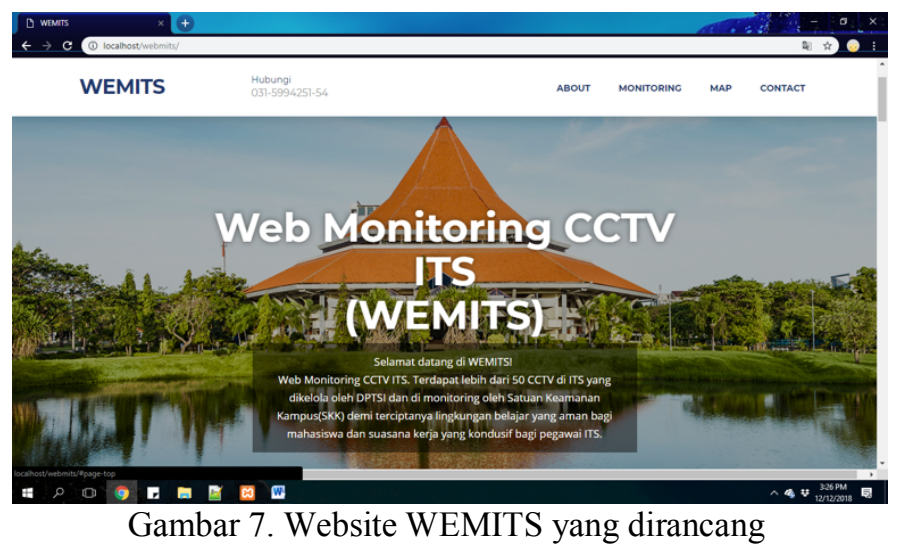

Pada page map, terdapat peta sebaran CCTV dengan dua indikator yaitu titik merah untuk CCTV mati dan titik hijau untuk CCTV menyala yang dapat mendeteksi otomatis kondisi ON/OFF CCTV setelah mengklik atau me-refresh page tersebut dengan syarat harus terkoneksi dengan LAN ITS baik menggunakan interface Ethernet maupun Wi-Fi. Berikut adalah Gambar 4.35 yang menunjukkan perubahan warna indikator pada peta sebaran CCTV ITS.
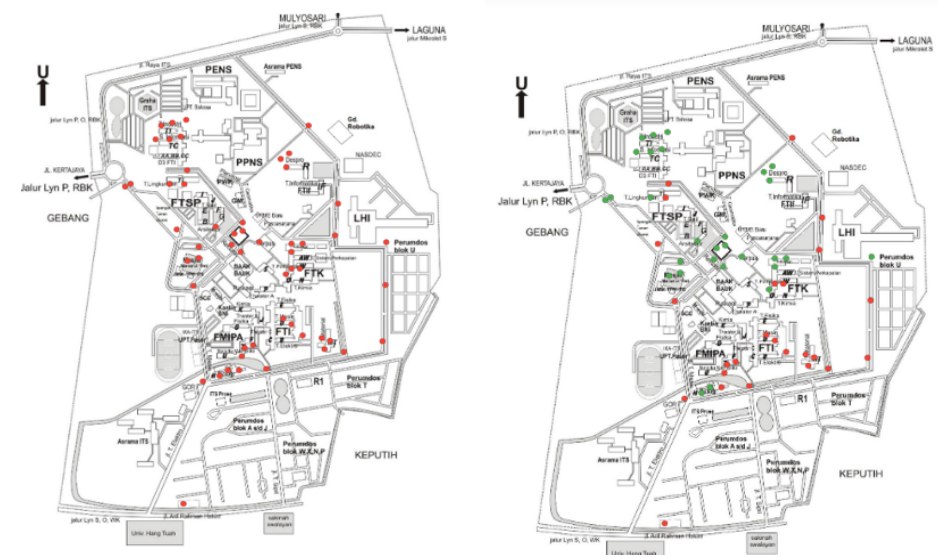

Gambar 8. Perubahan indikator sebelum (kiri) terhubung dan setelah (kanan) terhubung LAN ITS

Perubahan tidak akan terjadi jika client tidak terhubung dengan LAN ITS dikarenakan pada script web dibuat fungsi untuk melakukan ping ke variable IP-IP CCTV. Dari script diatas dapat dianalisis bahwa fungsi akan membaca halaman ping.php lalu menganalisis variable cam_ip. Jika result $==1$ maka titik indikator akan diisi dengan warna sesuai kode warna hexadecimal \#4caf50'. Jika IP yang di check ping memenuhi syarat, maka akan ditampilkan cam-inactive-list yang berisi identitas, IP dan lokasi CCTV yang tidak aktif.

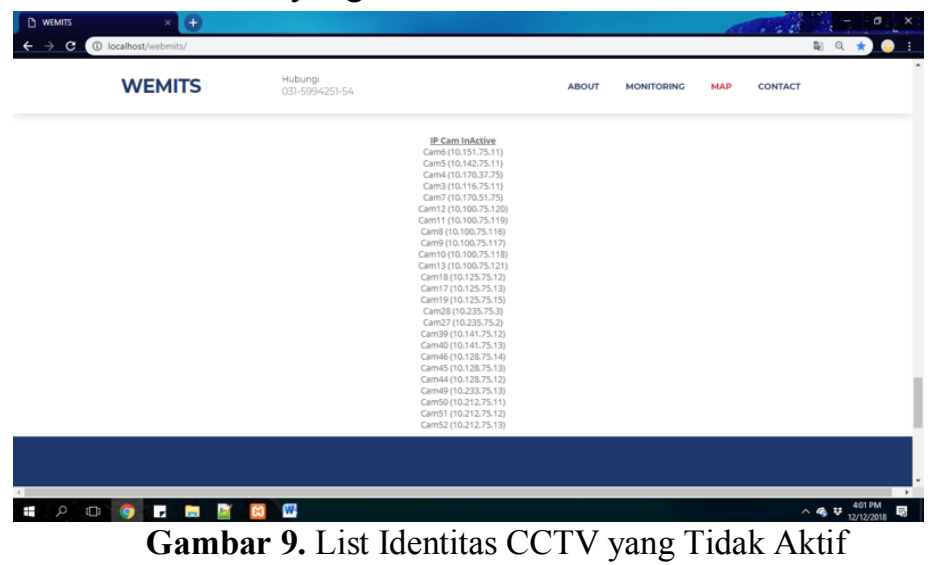


Setelah page-page yang dirancang dapat diakses, maka dilakukan pengukuran untuk melihat kinerja dari web. Pengukuran dilakukan pada komputer client, dengan mengukur nilai throughput saat jumlah CCTV menyala satu hingga dengan sepuluh CCTV. Hasil pengukuran dapat dilihat pada tabel 4.3 di bawah ini. Dapat diperhatikan bahwa saat web menampilkan sepuluh video secara langsung, throughput maksimal adalah $20 \mathrm{Mbps}$ dengan jitter $0.9 \mathrm{~ms}$.

Tabel 2. Pengkuran Kinerja Web

\begin{tabular}{|c|c|c|}
\hline $\begin{array}{c}\text { Jumlah } \\
\text { CCTV }\end{array}$ & $\begin{array}{c}\text { Throughput } \\
\text { (Mbps) }\end{array}$ & $\begin{array}{c}\text { Jitter } \\
\text { (s) }\end{array}$ \\
\hline 1 & 11,8 & 1.2 \\
\hline 2 & 24,63 & 0.9 \\
\hline 3 & 17,7 & 1,1 \\
\hline 4 & 27,76 & 0.8 \\
\hline 5 & 25,34 & 0.9 \\
\hline 6 & 37,34 & 0.6 \\
\hline 7 & 33,16 & 0.7 \\
\hline 8 & 33,71 & 0.7 \\
\hline 9 & 32,97 & 0.7 \\
\hline 10 & 20 & 0.9 \\
\hline
\end{tabular}

\section{KESIMPULAN}

Setelah melakukan evaluasi Jaringan Closed Circuit Television (CCTV) di ITS, didapatkan beberapa kesimpulan antara lain:

1. CCTV yang masih beroperasi di ITS sebanyak 28 buah dari jumlah total 54 buah,yaitu CCTV outdoor dengan Fiber Optik sebanyak 13 buah dan wireless sebanyak dua buah. Sementara itu, CCTV indoor menggunakan kabel UTP sebanyak 13 buah.

2. Jaringan CCTV ITS terdiri atas tiga yaitu lapisan akses, lapisan distribusi dan lapiran inti.

3. Throughput seluruh CCTV yang beroperasi dikategorikan Sangat Bagus menurut TIPHON (memiliki nilai diatas $1200 \mathrm{Kbps}$ ).

4. Jitter seluruh CCTV yang beroperasi di ITS dikategorikan Bagus menurut TIPHON (0-75 $\mathrm{ms})$.

5. Masalah utama jaringan CCTV adalah tidak dilakukannya perawatan dan perbaikan perangkat.

6. WEMITS merupakan website yang dirancang untuk me- monitoring CCTV secara otomatis dapat menampilkan indikator titik hijau untuk CCTV menyala dan titik merah untuk CCTV mati, serta list nama dan IP CCTV yang tidak menyala script pada fungsi function check_ping (xdatas, container) sehingga sangat memudahkan kerja petugas monitoring dalam melakukan pengawasan.

7. WEMITS memiliki throughput 20MBps dan jitter $0.9 \mathrm{~ms}$ dengan kondisi maksimal 10 CCTV yang menyala pada satu layar.

\section{DAFTAR PUSTAKA}

[1] Atmoko, Eko Hari. Membuat Sendiri CCTV berkelas Enterprise dengan Biaya Murah. Yogyakarta: Penerbit Andi. 2012.

[2] Ahmad, Afis Abror. Rancang Bangun dan Analisa QoS Audio dan Video Streaming pada Jringan MPLS VPN. Jurnal Tugas Akhir. Surabaya: PENS. 2014. 
[3] Prabowo, Septian Dwi. Analisa Perancangan dan Implementasi CCTV over IP Pada Jaringan Broadband Powerline Communication. E- Proceeding of Engineering. 2015; 2(2) ISSN: 23559365.

[4] Austerberry, David. The Technology of Video and Audio Streaming. Focal Press: USA, 2004. [5] Cahya, Panji Krisna, dkk. Perancangan Jaringan Local Area Network (LAN) Untuk Layanan Video Conference Dengan Standar Wifi 802.11g. Jurnal Tugas Akhir. Malang: Universitas Brawijaya. 2015.

[6] Nofrida, Rizki Amalia, dkk. Pengukuran dan Evaluasi QoS untuk Meningkatkan Kualitas Layanan Trafik Kamera CCTV. E-Proceeding of Applied Science. 2017; 3(3). ISSN: 2442-5826.

[7] Y Utama, Yadi. Sistem Informasi Berbasis Web Jurusan Sistem Informasi Fakultas Ilmu Komputer Universitas Sriwijaya. Jurnal Sistem Informasi (JSI). 2011; 3(2): 359-370.

[8] Diktat Pemrograman Web Berbasis Open Source. Bab IV Pengenalan HTML-1. Jakarta: Politeknik Negeri Jakarta. 2014. 